\title{
SISTEMAS MULTICOMPONENTES COM O ACETATO DE HECOGENINA: DOSEAMENTO E CARACTERIZAÇÃO
}

\author{
C.D.L.F.A.MOREIRA ${ }^{1}$, W.F.SILVA-JÚNIOR, J.G.O.PINHEIRO, Y.M.B.G. CARVALHO, \\ L.J.QUINTANS-JÚNIOR, A.A.S.ARAÚJO, A.A.N.LIMA \\ ${ }^{1}$ Universidade Federal do Rio Grande do Norte, Centro de Ciências da Saúde, Departamento \\ de Farmácia \\ ${ }^{2}$ Universidade Federal de Sergipe, Departamento de Fisiologia \\ carlosdemocedes@gmail.com
}

\begin{abstract}
RESUMO - $\mathrm{O}$ acetato de hecogenina pode ter sua atividade antihiperalgésica, melhorada com sistemas multicomponentes com ciclodextrinas e polímeros. Logo, o presente estudo visa desenvolver esses sistemas pelos métodos de mistura física e malaxagem, caracterizá-los por FTIR e doseá-los por CLAE. Os resultados do infravermelho mostraram uma melhor eficiência do método de malaxagem como forma de se obter tais sistemas. Além disso o resultado do doseamento e da eficiência de complexação mostraram uma maior concentração do protótipo. Logo, é interessante usar sistemas multicomponentes como alternativa para melhorar as propriedades físico-químicas e biológica desse' protótipo.
\end{abstract}

Palavras chave: Acetato de hecogenina, polímeros hidrofilicos, sistemas multicomponentes

\begin{abstract}
Hecogenin acetate may have its antihyperalgesic activity, enhanced with multicomponent systems with cyclodextrins and polymers. Therefore, the present study aims to develop these systems by methods of physical mixing and grinding, characterizing them by FTIR and dosing them by HPLC. The infrared results showed a better efficiency of the malaxing method as a way of obtaining such systems. In addition the result of the dosing and the efficiency of complexation showed a greater concentration of the prototype. Therefore, it is interesting to use multicomponent systems as an alternative to improve the physico-chemical and biological properties of this prototype.
\end{abstract}

Keywords: Hecogenin acetate, betacyclodextrin, polymers, multicomponent systems

\section{INTRODUÇÃ̃O}

O Acetato de hecogenina consiste em uma sapogenina acetilada que de acordo com a literatura, já apresenta algumas atividades farmacológicas comprovadas como anticâncer (Gama, 2013) e a mais importante é a anti-hiperalgésica (Quintans, 2015), por se ligar em receptores opióides e inibir consequentemente vias descendente de dor. Entretanto, devido à baixa solubilidade aquosa dessa classe de metabólitos secundários (Hostettman, 2005), nem sempre é viável veiculá-lo em formulações sólidas orais. 
Levando isso em consideração, há algumas alternativas para melhorar essa condição, e uma das mais utilizada é o desenvolvimento de complexos de inclusão com ciclodextrinas a partir da formação de complexos de inclusão. Entretanto, nem sempre a formação desse sistema é favorável devido ao alto peso molecular do sistema, baixa eficiência de complexação que prejudicam a estabilidade do sistema (Loftsson e Brewster, 2012). Nesse caso,a adição na formulação de terceiros componentes como polímeros hidrofílicos busca melhorar estabilizar o sistema e ainda mais as propriedades físico-químicas da substância. Logo, o presente trabalho visa: desenvolver sistemas multicomponentes com o acetato de hecogenina, ciclodextrinas e polímeros hidrofílicos (PEG 6000, PVP K-30, HPMC) com o intuito de avaliar a influência desses polímeros como um terceiro componente no sistema acetato de hecogenina/beta-ciclodextrina, além de caracterizar pela espectroscopia no infravermelho os sistemas e avaliar como o polímero altera a eficiência de complexação. Visando, assim, obter um sistema estável para que se possa ser interessante sua aplicação como alternativa viável para um novo sistema de liberação com esse protótipo.

\section{MATERIAIS E MÉTODOS}

Os materiais utilizados no estudo foram o acetato de hecogenina, betaciclodextrina, PVP K-30, e HPMC foram comprados a Sigma Aldrich, o PEG 6000 a Quemis. Todos os outros materiais utilizados foram de grau analítico. Os sistemas foram obtidos pelo método de misturas físicas e malaxagem na razão molar de 1:1 e 1:2 (protótipo/ciclodextrina) junto com $2,5 \%$ de cada polímero. Para caracterização físicoquímica foi feita pela Espectroscopia no Infravermelho por Transformada de Fourier. O doseamento dos sistemas foi realizado pelo método de cromatografia líquida de alta eficiência (CLAE), nas condições da coluna Agilent C18, temperatura de $25^{\circ} \mathrm{C}$, volume de injeção 1,5 mL e detector DAD. Levando em consideração a concentração teórica do acetato de hecogenina nos sistemas $1: 1$, sendo $91,6 \mathrm{ug} / \mathrm{mL}$, e nos sistemas $1: 2$, sendo $68,4 \mathrm{ug} / \mathrm{mL}$. Já para a Eficiência de Complexação (EE\%) foi feita para cada tipo de complexo de inclusão, dissolvendo $10 \mathrm{mg}$ de amostra em $10 \mathrm{~mL}$ de acetonitrila e deixaram-se durante $36 \mathrm{~h}$ após terem sido bem misturados $(250 \mathrm{rpm})$ seguidas de centrifugação a $3500 \mathrm{rpm}$ durante 30 minutos. $2 \mathrm{~mL}$ do sobrenadante foram recolhidos, filtrados num filtro de membrana de $0,45 \mu \mathrm{m}$ (PTFE) e analisados por CLAE. O EE\% foi calculado a partir da equação $=\mathrm{CE} \%=\frac{\text { contentofHAentrapped }}{\text { initialHAamount }} * 100$, onde temos a porcentagem de protótipo "aprisionado" e livre.

\section{RESULTADOS E DISCUSSÃO}

- Espectroscopia no infravermelho por Transformada de Fourier (FTIR) $\mathrm{O}$ espectro de infravermelho do acetato de hecogenina apresenta bandas características na região de aproximadamente $2900 \mathrm{~cm}^{-1}$ referente ao estiramento $\mathrm{C}-\mathrm{H}$, também nas regiões de $1740 \mathrm{~cm}^{-1}$ e $1704 \mathrm{~cm}^{-1}$ referentes ao grupo carbonila $\mathrm{C}=\mathrm{O}$ além da deformação angular e axial do grupo C-O do grupo éter na região de $1037 \mathrm{~cm}^{-1}$, tal resultado coincide com alguns já publicados na literatura (Moreira, 2018). Já o espectro da Betaciclodextrina apresenta bandas características nas regiões, $3340 \mathrm{~cm}^{-1}$ referentes a vibração da ligação $\mathrm{O}-\mathrm{H}, 2900 \mathrm{~cm}^{-1}$ referentes a ligação de estiramento C-H, entre 14001100 há grupos característicos da ligação $\mathrm{C}-\mathrm{O}$ do éter e entre $1000-700 \mathrm{~cm}^{-1}$ há grupos 
associados as ligações de estiramento $\mathrm{C}-\mathrm{H}$ e $\mathrm{C}-\mathrm{C}$ dos carbonos anel de glicopiranose.

Figura 1: Sistemas multicomponentes com os polímeros: HPMC(A), PVP(B) e $\operatorname{PEG}(\mathrm{C})$

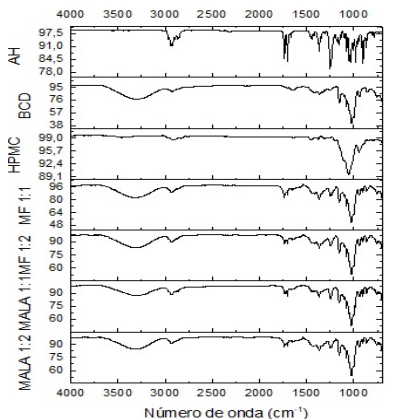

A

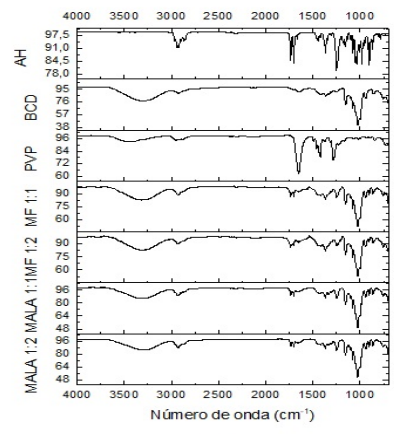

B

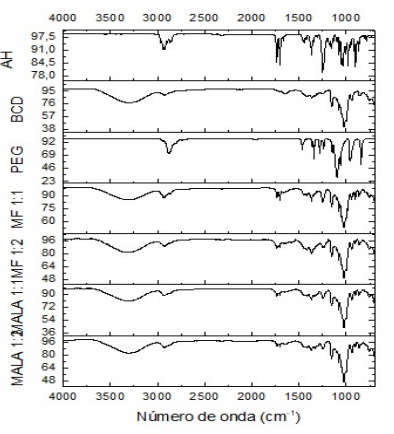

C

A substância apresenta tempo de retenção de 20,35 min. Ao avaliar os sistemas obtidos com o polímero HPMC na razão molar 1:1 e 1:2 (Figura 1A), com relação a mistura física (MF) é perceptível ver uma semelhança grande com o espectro da betaciclodextrina, apenas com algumas alterações na região de $1600-1700 \mathrm{~cm}^{-1}$ favorecendo a hipótese de formação dos complexos, entretanto com pouca interação química com o polímero HPMC. Quando vamos avaliar o método de malaxagem, vemos que há uma alteração no espectro que tende a ser mais parecido com o da betaciclodextrina, já que há a formação do complexo, e o objetivo é ver a influência desse polímero na complexação, vemos que na região de $1200-1250 \mathrm{~cm}^{-1}$ há o aparecimento de uma pequena banda, sugerindo uma interação química entre o HPMC e o complexo Além disso, os sistemas obtidos pelo método de malaxagem foram os mais propensos a interagir com o complexo.

Quando avaliamos os sistemas multicomponentes com o polímero PVP K-30, na razão molar 1:1 e 1:2, vemos a alta semelhança entre o espectro da beta-ciclodextrina com os sistemas, tanto obtidos por mistura física quanto nos malaxados, mostrando que há alterações significativas em pontos específicos de número de onda, aproximadamente em $1300 \mathrm{~cm}^{-1}$, evidenciando assim uma interação química, mais intensa quando os sistemas são obtidos pelo método de malaxagem.

Já os sistemas com o polímero PEG, é perceptível ver a semelhança entre os sistemas obtidos e a beta-ciclodextrina, provando que está havendo a formação do complexo, entretanto ainda há alterações sutis, na região de $1300-1400 \mathrm{~cm}^{-1}$. Assim, mostrando a eficiência da malaxagem.

\section{- Doseamento por HPLC}

Tendo os sistemas, o comportamento esperado é que os sistemas de misturas físicas 1:1 mostrem uma alta concentração do acetato de hecogenina, já que é apenas uma mistura física incapaz de viabilizar uma interação química entre os componentes do sistema. Levando em consideração que são avaliados a razão molar, tipo de polímero e o método de obtenção. Como é perceptível avaliar pela tabela que correlaciona a concentração pela área do pico cromatográfico, temos que a concentração do acetato de hecogenina varia em cada sistema, tendo as concentrações maior nos sistemas obtidos pelos métodos de malaxagem, exatamente no sistema 1:2 com o PEG 6000, 1:1 com o PVP K30 e 1:1 com o HPMC, mostrando a eficiência de tal método de obtenção. 
Figura 2: Tabela A: Doseamento , Tabela B: Eficiência de Complexação

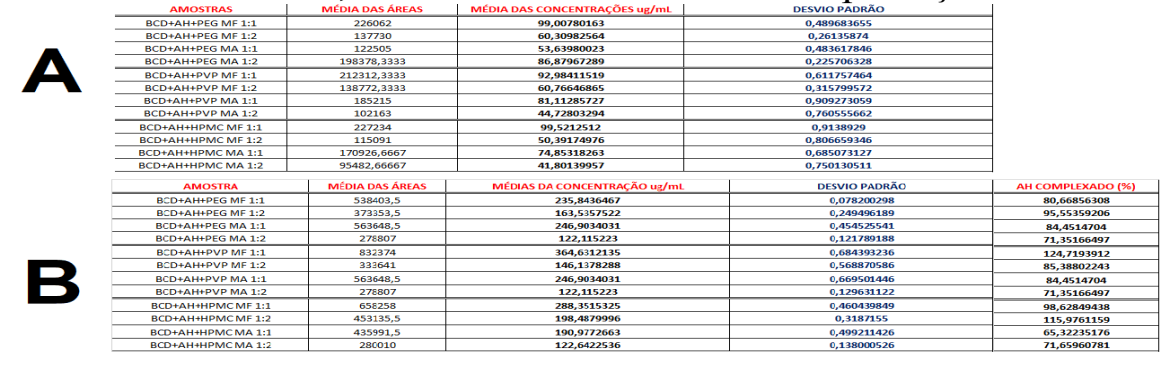

De acordo com os valores na tabela é perceptível ver que a adição dos polímeros como terceiro componente tende a aumentar os valores da eficiência de complexação, mostrando e provando assim que esses componentes são uma alternativa interessante para incrementar as características físico-químicas da formulação. Além disso, os resultados mais interessantes com cada polímero, aqueles que apresentaram maior eficiência de complexação tiveram como método de obtenção a malaxagem, já que os métodos de mistura física não viabilizam uma interação química entre os componentes do sistema.

\section{CONCLUSÃO}

Logo, diante dos resultados apresentados nesse trabalho, é possível concluir que tais sistenas de liberação acetato de hecogenina/betaciclodextrina é uma alternativa interessante para melhorar parâmetros físico-químicos como estabilidade, solubilidade e também suas propriedades farmacológicas.

\section{REFERÊNCIAS}

GAMA, Kelly Barbosa et al. Evidence for the involvement of descending pain-inhibitory mechanisms in the antinociceptive effect of hecogenin acetate. J. nat. prod., v. 76, n. 4, p. 559-563, 2013.

QUINTANS, Jullyana SS et al. Evidence for the involvement of spinal cord-inhibitory and cytokines-modulatory mechanisms in the anti-hyperalgesic effect of hecogenin acetate, a steroidal sapogenin-acetylated, in mice. Molecules, v. 19, n. 6, p. 8303-8316, 2014.

HOSTETTMANN, Kurt; MARSTON, Andrew. Saponins. Cambridge University Press, 2005.

LOFTSSON, Thorsteinn; BREWSTER, Marcus E. Cyclodextrins as functional excipients: methods to enhance complexation efficiency. J. pharm. sci, v. 101, n. 9, p. 3019-3032, 2012.

MOREIRA, Carlos Demócedes Luís de França Almeira et al. Amorphous solid dispersions of hecogenin acetate using different polymers for enhancement of solubility and improvement of anti-hyperalgesic effect in neuropathic pain model in mice. Biomed Pharmacother. v97, p.870 - 879, 2018. 